\title{
HYDROGEN EMBRITTLEMENT OF HIGH STRENGTH STEEL ELECTROPLATED WITH ZINC-COBALT ALLOYS
}

\author{
E.M.K.Hillier ${ }^{+} \&$ M.J.Robinson \\ School of Industrial \& Manufacturing Science \\ Cranfield University \\ ${ }^{+}$Present address; OIS plc, Aberdeen
}

\begin{abstract}
Slow strain rate tests were performed on quenched and tempered AISI 4340 steel to measure the extent of hydrogen embrittlement caused by electroplating with zinc-cobalt alloys. The effects of bath composition and $\mathrm{pH}$ were studied and compared with results for electrodeposited cadmium and zinc-10\%nickel. It was found that Zinc-1\%cobalt alloy coatings caused serious hydrogen embrittlement (EI 0.63); almost as severe as that of cadmium (EI 0.78). Baking cadmium plated steel for 24 hours at $200^{\circ} \mathrm{C}$ gave full recovery of mechanical properties but specimens plated with zinc- $1 \%$ cobalt and then baked still failed in $89 \%$ of the time of unplated controls. It was shown that hydrogen uptake and embrittlement could be controlled by depositing thin layers of cobalt or nickel at the steel/coating interface. For example, the least embrittlement was caused by zinc$10 \%$ nickel (EI 0.037) due to a nickel rich layer with very low hydrogen diffusion coefficient that formed during the initial stages of electroplating. Similarly, a 0.5 micron nickel layer was effective in lowering the embrittlement caused by zinc- $1 \%$ cobalt to that of zinc- $10 \%$ nickel. Furthermore, a 0.5 micron cobalt layer deposited before a zinc-1\%cobalt coating gave virtually $100 \%$ recovery of mechanical properties after baking.
\end{abstract}

\section{INTRODUCTION}

Electrodeposited zinc-cobalt alloys are possible alternatives to cadmium for sacrificial corrosion protection of steel components. The coatings contain typically $1-4 \%$ Co by weight and are produced by an anomalous co-deposition mechanism ${ }^{(1,2)}$ that promotes a zinc-rich alloy by suppressing the reduction of the more noble cobalt. The corrosion rate of electrodeposited zinc- $4 \% \mathrm{Co}$ is reported to be very similar to that of the more expensive zinc$14 \% \mathrm{Ni}^{(3)}$.

The possibility of hydrogen embrittlement is an important consideration when high strength steels are electroplated. Plating processes generally have a current efficiency of less than $100 \%$ and a proportion of the current passed during electrodeposition results in the generation of hydrogen, some of which becomes incorporated in the deposit and subsequently diffuses into the substrate. When hydrogen embrittlement is thought to be a risk a de-embrittlement treatment may be required. Following cadmium plating, for example, steels with a tensile strength over $1800 \mathrm{MPa}$ are baked for 24 hours at a temperature in the range $190-230^{\circ} \mathrm{C}^{(4)}$.

The aim of the work described in this paper was to investigate the extent to which electroplating with zinc-cobalt alloys causes hydrogen embrittlement of high strength steel. Slow strain rate tests were carried out on plated tensile specimens to measure the effect of the absorbed hydrogen on the loss of the steel's mechanical properties and the effectiveness of post-plating baking treatments in restoring these properties. For comparison, further tests were conducted on specimens plated with pure zinc, $\mathrm{Zn}-10 \% \mathrm{Ni}$ and cadmium and also with $\mathrm{Zn}-12 \% \mathrm{Co}-9 \% \mathrm{Fe}$ to investigate ways in which hydrogen uptake could be controlled by the coating composition. 


\section{METHODS}

\section{Materials}

The high strength steel AISI 4340 was selected for the slow strain rate tests due to its known susceptibility to hydrogen embrittlement in the quenched and tempered condition. The composition of the material is shown in Table 1.

Table 1 Composition of AISI 4340 Steel

\begin{tabular}{|l|l|l|l|l|l|l|l|l|l|}
\hline$\% \mathrm{C}$ & $\% \mathrm{Mn}$ & $\% \mathrm{Si}$ & $\% \mathrm{Cr}$ & $\% \mathrm{Ni}$ & $\% \mathrm{Mo}$ & $\% \mathrm{Al}$ & $\% \mathrm{Cu}$ & $\% \mathrm{~S}$ & $\% \mathrm{P}$ \\
\hline 0.41 & 0.79 & 0.23 & 0.88 & 1.67 & 0.22 & 0.024 & 0.13 & 0.003 & 0.009 \\
\hline
\end{tabular}

\section{Zinc-Cobalt Electroplating}

Zinc-cobalt electrodeposits were produced from an acid sulphate bath of composition shown in Table 2. The electrolyte contained $8 \%$ Co and was similar to that used commercially, except that no brighteners were added. A small quantity of the surfactant Teepol was included to avoid the formation of hydrogen bubbles that could lead to defects in the coating.

Table 2 Composition of the zinc-cobalt plating bath

\begin{tabular}{|l|c|}
\hline Addition & Concentration $\left(\mathbf{m o l ~ d m} \mathbf{~ m}^{-3}\right)$ \\
\hline $\mathrm{ZnSO}_{4} 7 \mathrm{H}_{2} \mathrm{O}$ & 1.739 \\
\hline $\mathrm{CoSO}_{4} 7 \mathrm{H}_{2} \mathrm{O}$ & 0.17 \\
\hline $\mathrm{NaSO}_{4}$ & 0.352 \\
\hline $\mathrm{CH}_{3} \mathrm{COONa}$ & 0.11 \\
\hline Teepol & 0.001 \\
\hline
\end{tabular}

The standard bath condition, which was used for the majority of the experiments, was a $\mathrm{pH}$ of 4.2 and a temperature of $50^{\circ} \mathrm{C}$. The resulting coatings were even and shiny, with a maximum cobalt content of $1 \%$. Plating for 15 minutes at a current density of $10 \mathrm{mAcm}^{-2}$ gave an average coating thickness of $8 \mu \mathrm{m}$, which is generally specified for threaded components.

The cadmium plating was carried out by a commercial electroplater and the coatings of pure zinc, zinc-10\%nickel and zinc-12\%cobalt-9\%iron were plated in the laboratory from the electrolytes shown in Table 3. 
Table 3 Compositions of the other plating solutions

\begin{tabular}{|c|c|c|c|c|c|c|}
\hline Coating & Current & Time & pH & Temp & Electrolyte & Concentration \\
\hline & $\left(\mathrm{mAcm}^{-2}\right)$ & (mins) & & $\left({ }^{\circ} \mathrm{C}\right)$ & & $\left(\mathrm{mol} \mathrm{dm}^{-3}\right)$ \\
\hline $100 \% \mathrm{Zn}$ & 10 & 15 & 1 & 50 & $\begin{array}{l}\mathrm{ZnSO}_{4} \cdot 7 \mathrm{H}_{2} \mathrm{O} \\
\mathrm{H}_{2} \mathrm{SO}_{4}\end{array}$ & $\begin{array}{l}1.2 \\
0.6\end{array}$ \\
\hline $\begin{array}{l}92-89 \% \mathrm{Zn} \\
8-11 \% \mathrm{Ni}\end{array}$ & 20 & 15 & 5 & 25 & $\begin{array}{l}\mathrm{ZnSO}_{4} .7 \mathrm{H}_{2} \mathrm{O} \\
\mathrm{NiSO}_{4} .7 \mathrm{H}_{2} \mathrm{O}\end{array}$ & $\begin{array}{l}0.92 \\
0.08\end{array}$ \\
\hline $\begin{array}{l}79 \% \mathrm{Zn} \\
12 \% \mathrm{Co} \\
9 \% \mathrm{Fe}\end{array}$ & 30 & 10 & 3 & 43 & $\begin{array}{l}\mathrm{ZnSO}_{4} \cdot 7 \mathrm{H}_{2} \mathrm{O} \\
\mathrm{CoSO}_{4} \cdot 7 \mathrm{H}_{2} \mathrm{O} \\
\mathrm{FeSO}_{4} \cdot 7 \mathrm{H}_{2} \mathrm{O} \\
\mathrm{Na}_{2} \mathrm{SO}_{4} \cdot 7 \mathrm{H}_{2} \mathrm{O} \\
\mathrm{CH}_{3} \mathrm{COONa}_{3} \mathrm{H}_{2} \mathrm{O} \\
\mathrm{H}_{2} \mathrm{SO}_{4}\end{array}$ & $\begin{array}{l}0.4 \\
0.4 \\
0.06 \\
2.5 \\
0.3 \\
0.5\end{array}$ \\
\hline
\end{tabular}

\section{Hydrogen Embrittlement Tests}

Tensile specimens for slow strain rate embrittlement testing were machined by CNC turning from normalised $6 \mathrm{~mm}$ diameter rod to give a $25 \mathrm{~mm}$ gauge length of $2.25 \mathrm{~mm}$ diameter. They were then hardened by heating in a neutral salt bath at $835-840^{\circ} \mathrm{C}$ for 15 minutes, followed by an oil quench at room temperature. Tempering was carried out at $250^{\circ} \mathrm{C}$ for 2 hours to give a mean hardness of $528 \mathrm{HV}_{10}$ and a mean tensile strength of $1850 \mathrm{MNm}^{-2}$. The tempering temperature of $250^{\circ} \mathrm{C}$ was chosen to avoid further change in mechanical properties when the specimens were later de-embrittled by baking for 24 hours at $200^{\circ} \mathrm{C}$.

The specimens were prepared for plating by abrading with silicon carbide paper, followed by degreasing in isopropanol. Pickling and anodic or caustic cleaning were not used to avoid hydrogen uptake. The slow strain rate tests were started immediately after plating, except for those specimens commercially plated with cadmium, which were stored in liquid nitrogen to prevent loss of absorbed hydrogen until they could be tested.

The specimens were tested on a Cortest slow strain rate machine at a strain rate of $1.1 \times 10^{-6}$ $\mathrm{s}^{-1}$ and the times to failure were recorded. In all, twenty-five specimens were tested in the unplated condition to act as controls. The extent of the embrittlement caused by each plating treatment was assessed by carrying out slow strain rate tests on five or more specimens in the as-plated condition. Additionally, the effectiveness of thermal de-embrittlement was measured by testing further specimens after first plating and then baking for 24 hours at $200^{\circ} \mathrm{C}$

\section{RESULTS}

Hydrogen embrittlement tests often display a range of times to failure when carried out under apparently identical experimental conditions. This is due to the variation in the number, size and distribution of microstructural flaws within the material at which hydrogen accumulates and leads to fracture. In this work Weibull statistics was used to distinguish between the effects of each of the experimental variables. 


\section{Weibull Model of Failure Times}

It can be shown that for a Weibull model the probability, $\mathrm{P}_{\mathrm{s}}$, of a specimen not failing within time, $\mathrm{t}$, is given by;-

$$
P_{s}=1-P_{t}=e^{-x t}
$$

Where $P_{t}$ is the probability of failure and $x$ is a shape parameter termed the Weibull slope ${ }^{(5-7)}$. In the present context $x$ represents the probability per unit time that during time, $t$, a crack will form in the specimen of sufficient size to cause failure. The value of $\mathrm{x}$ can be obtained from the negative gradient of a graph of $\ln \mathrm{P}_{\mathrm{s}}$ against $\mathrm{t}$. A schematic Weibull plot of failure times is shown in Fig 1. The graph is displaced along the time axis by the amount $t_{i}$, known as the minimum crack incubation time. (When $P_{s}=1$, then $\ln P_{s}=0$ and $t=t_{i}$ ).

Equation [3] can be modified to include $t_{i}$

$$
P_{s}=1-P_{t}=e^{-x(t-t)}
$$

\section{Unplated Specimens}

A Weibull plot of the times to failure in the slow strain rate tests for specimens that had been quenched and tempered but not electroplated is shown in Fig 2. All of the specimens failed in times ranging between 17 and 21 hours with a mean time of 18.9 hours.

\section{Effect of Zinc-Cobalt and Cadmium Plating}

The effect of electroplating specimens with 8 microns of cadmium or zinc-1\%cobalt was to promote hydrogen embrittlement of the steel and reduce the times to failure. The results for these two coatings are compared in Fig 3. The cadmium caused more embrittlement with a mean time to failure of 4.2 hours compared to 7.0 hours for the zinc-cobalt.

After baking at $200^{\circ} \mathrm{C}$ for 24 hours to promote loss of hydrogen from the surface, specimens that had been plated with cadmium showed full recovery of mechanical properties and the mean time to failure was restored to that of the unplated controls (Fig 4). The statistical Student t-test ${ }^{(8)}$ was used to confirm (95\% confidence) that the failure times of the baked cadmium plated specimens and the control specimens were part of the same population. Similarly, it was demonstrated that the baking heat-treatment did not affect the times to failure of the control specimens. In contrast, baking the zinc-cobalt plated specimens for 24 hours gave incomplete recovery and the times to failure were still only $89 \%$ of those for the controls. Additional tests were performed in which the baking time was increased to 48 hours but their recovery only increased to $91 \%$.

The $\mathrm{pH}$ of the zinc-cobalt plating bath had an influence on the times to failure, as shown by the results in Table 4. Raising the $\mathrm{pH}$ from the standard condition of 4.2 to a value of 5 decreased the time to failure whereas plating at $\mathrm{pH} 1$, which might have been expected to increase the hydrogen uptake, had the effect of reducing the hydrogen embrittlement. The reasons for these changes are discussed later. 
Table 4 Effect of $\mathrm{Zn}$-Co bath $\mathrm{pH}$ on failure times in slow strain rate tests

\begin{tabular}{|c|c|}
\hline Bath pH & Time to Failure (hours) \\
\hline 1 & 7.2 \\
\hline 3 & 6.3 \\
\hline 4.2 & 7.0 \\
\hline 5 & 4.5 \\
\hline
\end{tabular}

\section{Comparison with Pure Zinc Plating}

In order to investigate the embrittlement promoted by zinc-cobalt coatings in more detail, comparison was made with the times to failure of specimens electroplated with pure zinc. It was found that pure zinc promoted more embrittlement than zinc-1\%cobalt, with a mean time to failure of 5.6 hours, as shown in Fig 5. The presence of just 1\%Co in the zinc-cobalt alloy was beneficial in reducing the extent of embrittlement. Like the zinc-1\%cobalt coating, baking the pure zinc plated specimens did not fully restore their mechanical properties and they failed in $87 \%$ of the time of the unplated controls.

\section{Zinc-10\%Nickel Plating}

The results for electroplated Zn-10\%nickel are included in Fig 5. The mean time to failure of 18.2 hours indicates that very little hydrogen embrittlement was promoted by this coating. It had been shown in an earlier study ${ }^{(9)}$ that the reason that zinc-nickel alloys cause only a low level of embrittlement is that the first material to deposit on the surface of the steel has a higher nickel content than the remainder of the coating. Nickel has a very low diffusion coefficient for hydrogen ${ }^{(10)}$, in the order of $8 \times 10^{-10} \mathrm{~cm}^{2} \mathrm{~s}^{-1}$, and the nickel-rich interlayer acts as a barrier to the diffusion of hydrogen from the coating into the steel.

In the case of the zinc- $1 \%$ cobalt coatings it was expected that a cobalt-rich layer would form at the coating/substrate interface. If cobalt also acts as a barrier to hydrogen then this would explain why these coatings caused less hydrogen embrittlement than pure zinc coatings.

\section{Effects of Nickel and Cobalt Interlayers}

To test this hypothesis tests were carried out in which the slow strain rate specimens were electroplated by a double bath treatment (DBT); first with a 0.5 micron interlayer of either pure cobalt or pure nickel, followed by 8 microns of zinc, zinc- $10 \%$ cobalt or zinc-10\%nickel. The results for each of these coatings are shown in Fig 6. The least embrittlement was caused by electroplating a zinc-10\%nickel coating over a 0.5 micron layer of nickel, confirming the beneficial effects of nickel as a barrier to hydrogen diffusion. A particularly significant result is that the nickel interlayer was also effective in lowering the embrittlement of a zinc-cobalt coating to that of zinc-nickel. This could have important practical benefits as a means of producing zinc-cobalt coatings with the minimum risk of causing hydrogen embrittlement.

The cobalt interlayer also appeared to reduce the extent of embrittlement but it was not nearly as effective as the interlayer of nickel (Fig 6). The results for zinc-cobalt deposited over 0.5 microns of cobalt were very similar to those for zinc over cobalt and to those of zinc-cobalt alone. Surprisingly zinc-nickel, when plated by itself, caused little embrittlement but when coated over cobalt gave a similar amount of embrittlement to these other coatings. It would appear that in each case the level of embrittlement was controlled by the hydrogen trapped in the cobalt layer at the steel surface rather than that in the remainder of the coating. 


\section{Influence of Baking Treatment}

The effects of baking the zinc-cobalt coatings with the cobalt and nickel interlayers are shown in Fig 7. An important observation was that in both cases virtually full recovery was achieved. As baking the zinc-cobalt coating that did not have an interlayer failed to restore its properties to those of the unplated controls it is assumed that the presence of a thin layer of cobalt can have a significant effect. It is thought that a cobalt interlayer acts as a sufficient barrier to hydrogen that during baking the hydrogen in the coating escapes to atmosphere rather than diffusing into the steel.

\section{Zinc-Cobalt-Iron Plating}

The results for the zinc-12\%cobalt-9\%iron alloy were very promising as shown in Fig 8 . This coating was the least embrittling of the zinc-cobalt alloys tested with a mean time to failure of 10.8 hours compared to 5.6 hours for zinc, 7.0 hours for zinc-1\%cobalt and 7.2 hours for zinc-cobalt plated over a cobalt interlayer.

\section{Embrittlement Indices}

The extent of hydrogen embrittlement caused by a particular process is frequently assessed by comparing values of the embrittlement index (EI), which is defined as;-

$$
\mathrm{EI}=1-\left(\mathrm{t}_{\mathrm{p}} / \mathrm{t}_{\mathrm{c}}\right)
$$

where $t_{p}$ and $t_{c}$ are the times to failure of the plated specimens and controls respectively. The mean embrittlement indices for the different plating processes are compared in Table 5 . Clearly, the indices depend on the susceptibility of the steel in addition to the tendency of the electrodeposit to promote hydrogen uptake but values above 0.6 are generally taken to indicate severe embrittlement.

\section{Table 5 Embrittlement indices for each plating process}

\begin{tabular}{|l|c|}
\hline \multicolumn{1}{|c|}{ Coating } & Embrittlement Index \\
\hline Cadmium & 0.78 \\
\hline Zn & 0.7 \\
\hline Zn-1\%Co (pH 4.2) & 0.63 \\
\hline Zn-1\%Co baked & 0.11 \\
\hline Zn-Co-Fe & 0.43 \\
\hline Zn-10\%Ni & 0.037 \\
\hline
\end{tabular}

\section{DISCUSSION}

The results show that electrodeposited $\mathrm{Zn}-1 \% \mathrm{Co}$ coatings promote high levels of hydrogen embrittlement in a susceptible high strength steel substrate (Fig 3). This embrittlement was much greater than that caused by $\mathrm{Zn}-10 \% \mathrm{Ni}$ plating but not quite as severe as that for pure zinc or cadmium (Figs 3,5 \& Table 5). 


\section{Noble Metal Enrichment}

The lower risk of embrittlement from zinc-10\%nickel coatings is attributed to the deposition of a nickel-rich layer in the first stages of electroplating ${ }^{(9)}$. Nickel is an effective barrier to hydrogen uptake by the steel from the coating as it has a very low coefficient for hydrogen diffusion ${ }^{(10)}$. This conclusion is supported by the results for the dual bath treatments in which a 0.5 micron layer of nickel deposited beneath a zinc- $1 \%$ cobalt layer reduced hydrogen embrittlement to the level caused by zinc-10\%nickel alone (Fig 6).

The nickel-rich layer forms initially during electrodeposition by a 'normal' plating process as nickel is electrochemically a more noble element than zinc. It is only after the $\mathrm{pH}$ at the cathode surface has risen to 5.3 that whiskers of zinc hydroxide form, suppressing nickel deposition and allowing zinc to be reduced and deposited by the anomalous codeposition mechanism ${ }^{(11)}$.

It was expected that a cobalt-rich layer would form in a similar way in the early stages of zinc-cobalt electroplating and that the presence of this layer was responsible for the partial reduction in the severe embrittlement caused by pure zinc coatings. Indeed, a cobalt-rich layer, containing $7 \% \mathrm{Co}$, was detected at the coating/substrate interface using EDX and Auger electron spectroscopy ${ }^{(12)}$ and other published work on a similar electroplated zinc-cobalt alloy reported that an initial layer containing $10 \%$ cobalt forms in the early stages of plating (13). In the present study, thicker cobalt-rich layers were formed in deposits plated at a lower bath $\mathrm{pH}$, due to the longer time needed to establish the surface $\mathrm{pH}$ of 5.3 for the onset of anomalous codeposition. The longest time to failure and the lowest hydrogen uptake occurred with deposits plated at $\mathrm{pH} \mathrm{1,} \mathrm{where} \mathrm{the} \mathrm{thickest} \mathrm{cobalt-rich} \mathrm{layer} \mathrm{was} \mathrm{formed.}$ Conversely, the shortest times and highest hydrogen uptake corresponded to plating at $\mathrm{pH} 5$ at which the least cobalt enrichment took place.

\section{Effectiveness of Baking Treatment}

The results in Fig 4 showed that although the baking treatment was effective in removing absorbed hydrogen and reducing the risk of embrittlement in cadmium plated steel it did not give full recovery with zinc-cobalt alloy coatings. The specimens still failed in $89 \%$ of the time of the unplated controls, which was similar to the behaviour of specimens plated with pure zinc. Even after baking, the risk of an embrittlement failure in a zinc-cobalt plated specimen was greater than that for zinc- $10 \% \mathrm{Ni}$ plating without a baking treatment (Table 5).

It is possible that the zinc and zinc-cobalt electrodeposits were in a form that was relatively impervious to hydrogen so that it did not all escape to atmosphere during baking. In these circumstances, a proportion of the hydrogen would remain trapped in the steel and may lead to a delayed failure when a stress is subsequently applied.

The composition of the first deposit to form on the substrate has a controlling effect both on hydrogen uptake and its loss from the surface during baking. When a 0.5 micron cobalt interlayer was deposited beneath a zinc- $1 \%$ cobalt coating nearly $100 \%$ recovery of properties was achieved by baking. The cobalt interlayer is thought to have acted as a barrier to hydrogen so that during baking the hydrogen in the coating escaped to atmosphere rather than diffusing into the steel. 


\section{CONCLUSIONS}

[1] Zinc-1\%cobalt alloy coatings electrodeposited on a quenched and tempered AISI 4340 high strength steel substrate resulted in serious hydrogen embrittlement of the steel (Embrittlement Index 0.63). However, this embrittlement was less severe than that caused by cadmium or zinc electroplating (Embrittlement Indices 0.78 and 0.7 respectively).

[2] The least embrittlement from zinc-1\%cobalt occurred when the coatings were deposited at $\mathrm{pH} 1$ due to the formation of a cobalt-rich layer at the coating/substrate interface. In contrast, the greatest embrittlement arose from plating at $\mathrm{pH} 5$ when the cobalt-rich layer was not detected.

[3] The mechanical properties of cadmium electroplated specimens recovered fully after a 24 hour baking treatment at $200^{\circ} \mathrm{C}$, whereas specimens that had been plated with zinc- $1 \%$ cobalt and then baked still failed in $89 \%$ of the time of unplated controls.

[4] Even after a baking treatment, the risk of an embrittlement failure in a zinc-1\%cobalt plated specimen was greater than that caused by an unbaked zinc-10\%nickel plating.

[5] A 0.5 micron cobalt interlayer deposited before the zinc- $1 \%$ cobalt coating gave virtually $100 \%$ recovery of mechanical properties after baking. It is thought that the cobalt layer acted as a sufficient barrier to hydrogen that during the baking treatment the hydrogen in the coating escaped to atmosphere rather than diffusing into the steel.

[6] Of the coatings tested, the least hydrogen embrittlement was caused by electroplated zinc-10\%nickel (Embrittlement Index 0.037). This was attributed to the formation of a layer at the coating/substrate interface that was enriched in nickel, which is known to have a very low hydrogen diffusion coefficient.

[7 ] A 0.5 micron nickel interlayer was effective in lowering the embrittlement caused by zinc- $1 \%$ cobalt to that of zinc- $10 \%$ nickel. This finding offers a practical method of reducing the risk of embrittlement associated with zinc-cobalt coatings.

[8] The results for the zinc- $12 \%$ cobalt-9\%iron alloy were very promising as this coating caused the least embrittlement of the zinc-cobalt alloys tested (Embrittlement Index 0.43).

Acknowledgement; The authors acknowledge QinetiQ, Farnborough for the support of this work funded through the MOD Corporate Research Programme 


\section{REFERENCES}

[1] A Brenner, Electrodeposition of Alloys, Vol 1, Academic Press, New York, p 75, (1963)

[2] K.Higashi, H.Fukushima, T.Urakawa, T.Adaniya \& K.Matsudo, 'Mechanism of the Electrodeposition of Zinc Alloys Containing a Small Amount of Cobalt.' J.Electrochem. Soc., Vol 128, No 10, pp 2081-2085, (1981)

[3] A.Abibsi, N.Short \& K.Denis, Corrosion Resistance of Zinc Alloy Coatings, Trans. Inst. Metal Finishing, Vol 67, pp 73-77, (1991)

[4] Defence Standard 03-4/2, 'The Pre-Treatment and Protection of Steel Parts of Specified Maximum Tensile Strength Exceeding $1450 \mathrm{Nmm}^{-2}$, (1977)

[5] E.Strecker, D.A.Ryder \& T.J.Davies, 'An Investigation of Hydrogen Induced Delayed Failure in Un-notched Specimens of 0.9\%C Steel Strip', Iron \& Steel Inst., 207, 1639-1641, (1968)

[6] M.J.Robinson \& R.M.Sharp, 'The Effect of Post-Exposure Heat Treatment on the Hydrogen Embrittlement of High Carbon Steel', Corrosion, 41, (10), pp 582-586, (1985)

[7] J.R.Nicholls \& P.Hancock, 'The Analysis of Oxidation and Hot Corrosion Data - A Statistical Approach', High Temperature Corrosion, NACE-6, R.Rapp, Ed., National Association of Corrosion Engineers, Houston, Texas, p 198, (1983)

[8] C.Chatfield, 'Statistics for Technology - A Course in Applied Statistics', Publ. Chapman \& Hall, Second Edition, (1978)

[9] M.J.Carr \& M.J.Robinson, 'The Effects of Zinc Alloy Electroplating on the Hydrogen Embrittlement of High Strength Steels', Trans. I.M.F., 73, (2), pp 58-64, (1995)

[10] T.M.Harris, 'Hydrogen Diffusion and Trapping in Electrodeposited Nickel', $\mathrm{PhD}$ thesis, Massachusetts Institute of Technology, (1989)

[11] K.R.Baldwin, C.J.E.Smith \& M.J.Robinson, 'A Study into the Electrodeposition Mechanisms of Zinc-Nickel Alloys from an Acid-Sulphate Bath', Trans. I.M.F., 72, (2), pp 79-88, (1994)

[12] E.M.K.Hillier, 'The Effect of Zinc-Cobalt Electroplating on the Hydrogen Embrittlement of High Strength Steel', PhD thesis, Cranfield University, (2001)

[13] J.Downes, 'Structure and Morphology of Electroplated Zinc/Zinc-Cobalt Alloy Coatings', PhD Thesis, Nottingham University, (1994) 


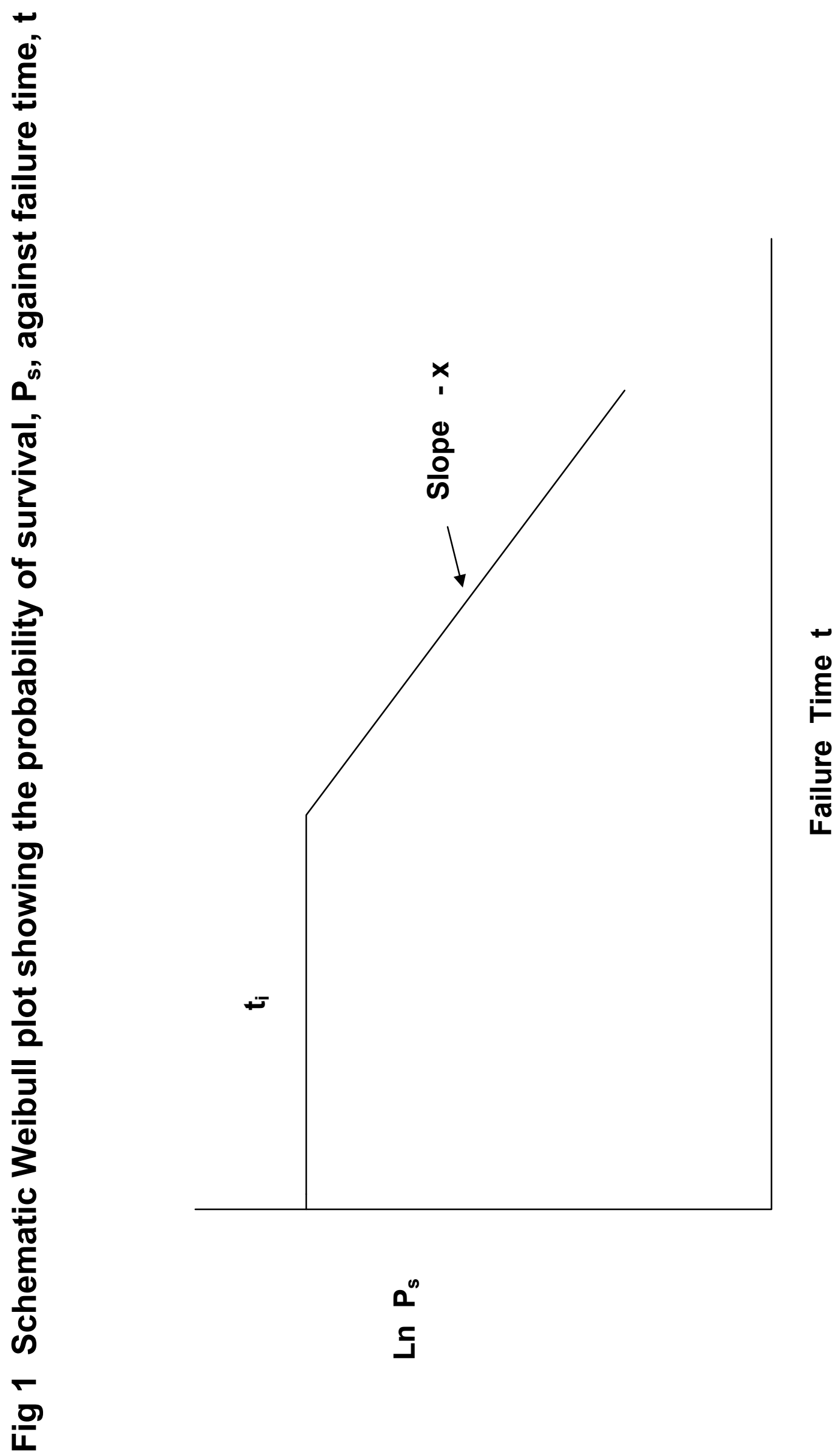




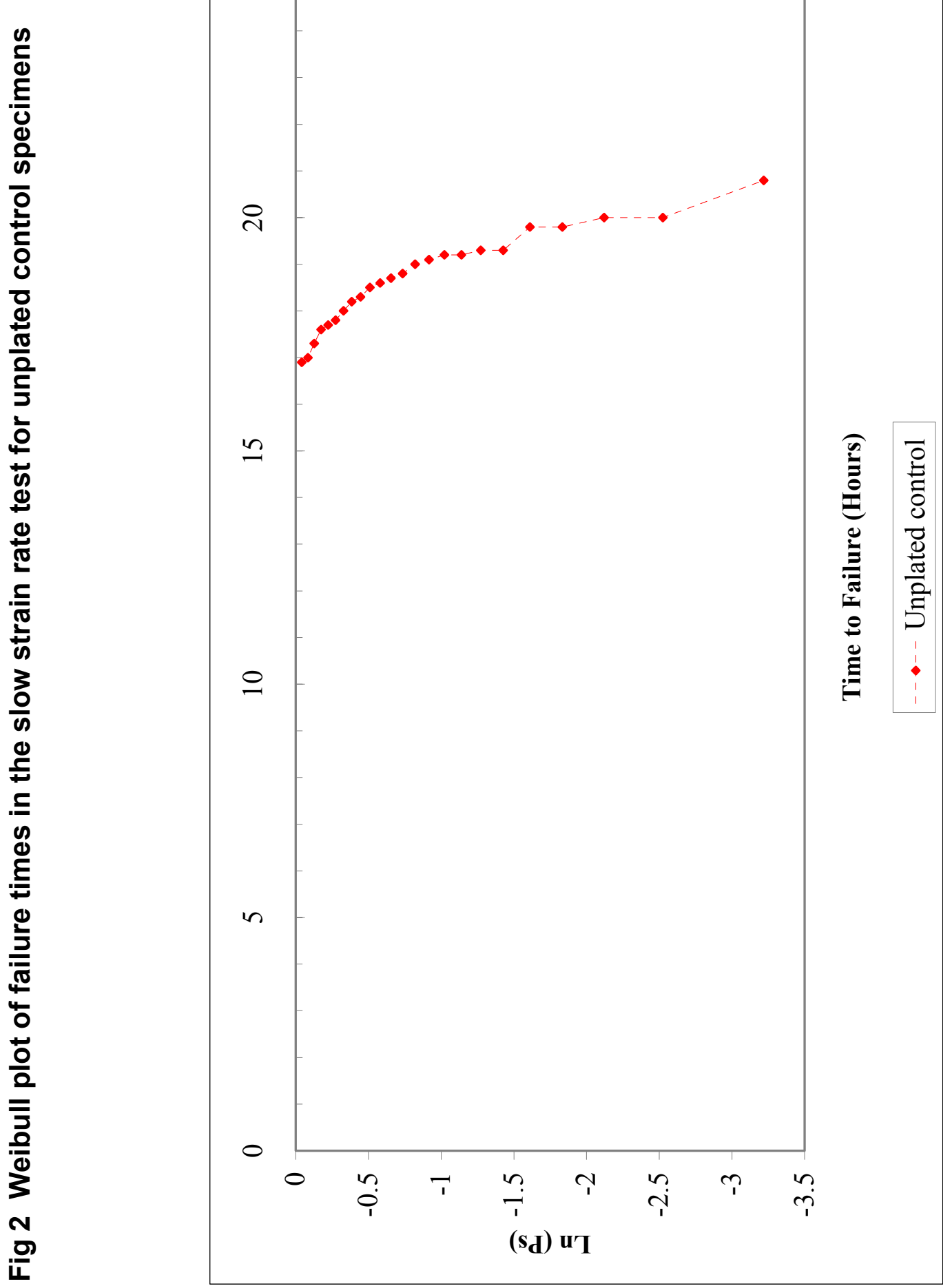




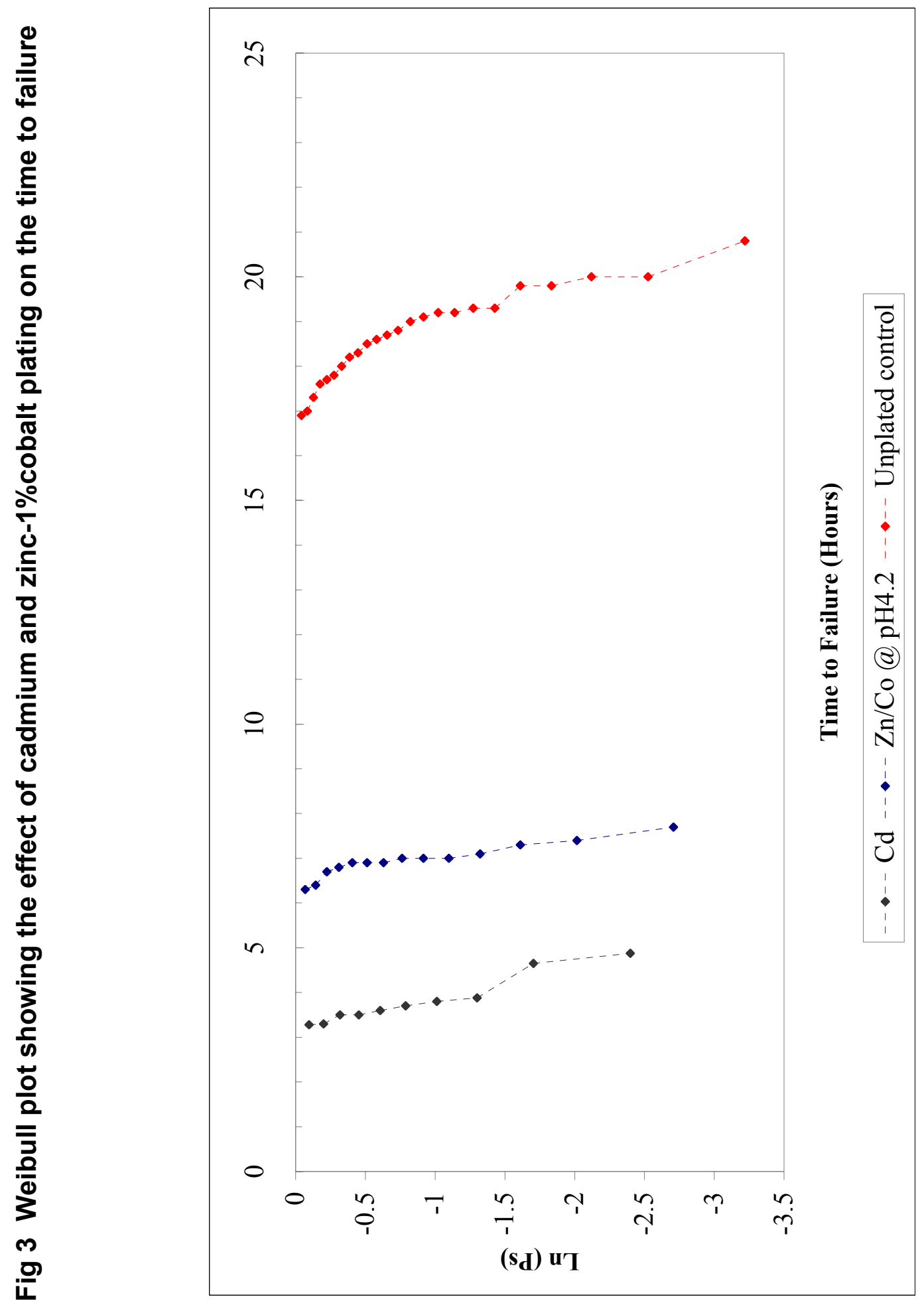



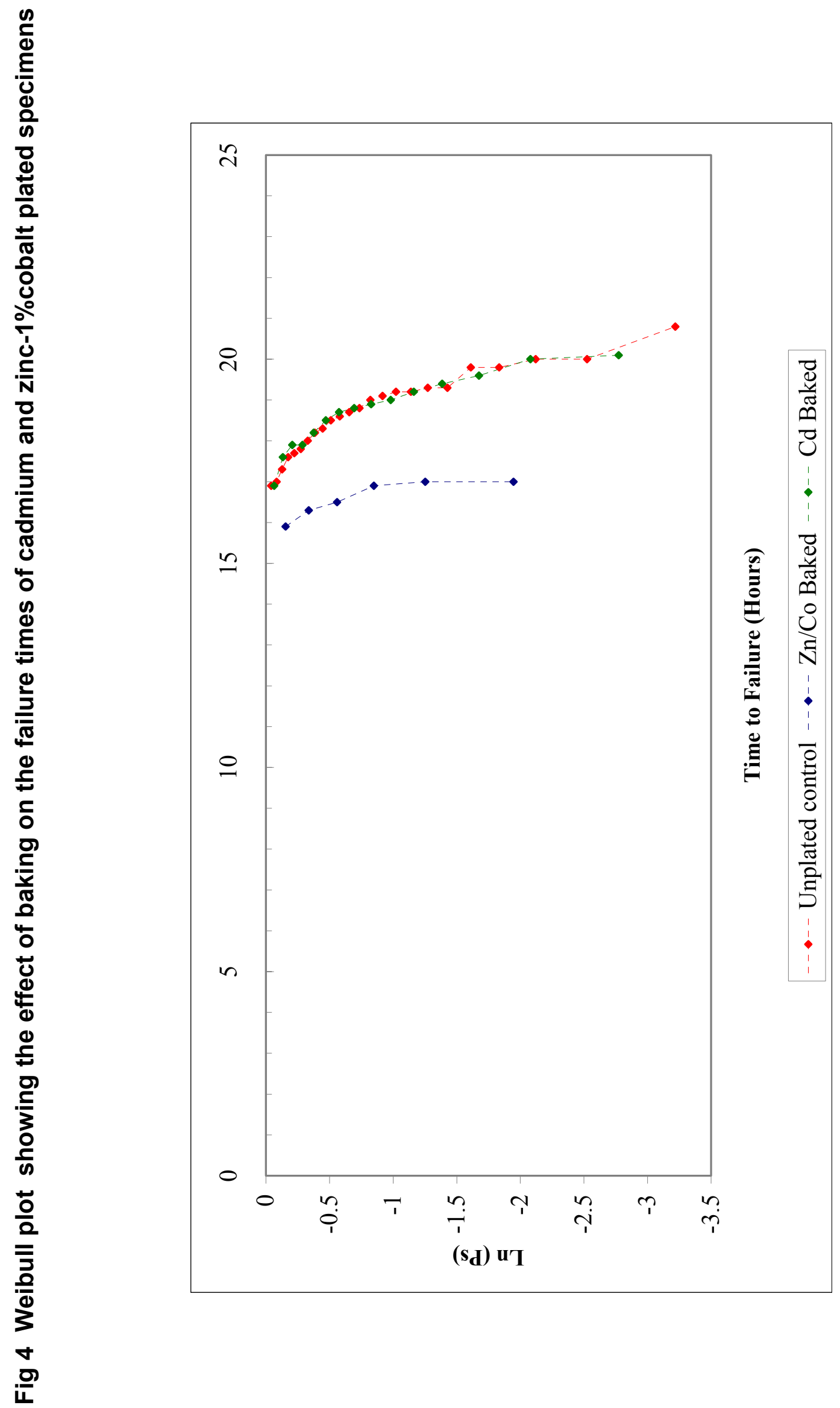

무 모 


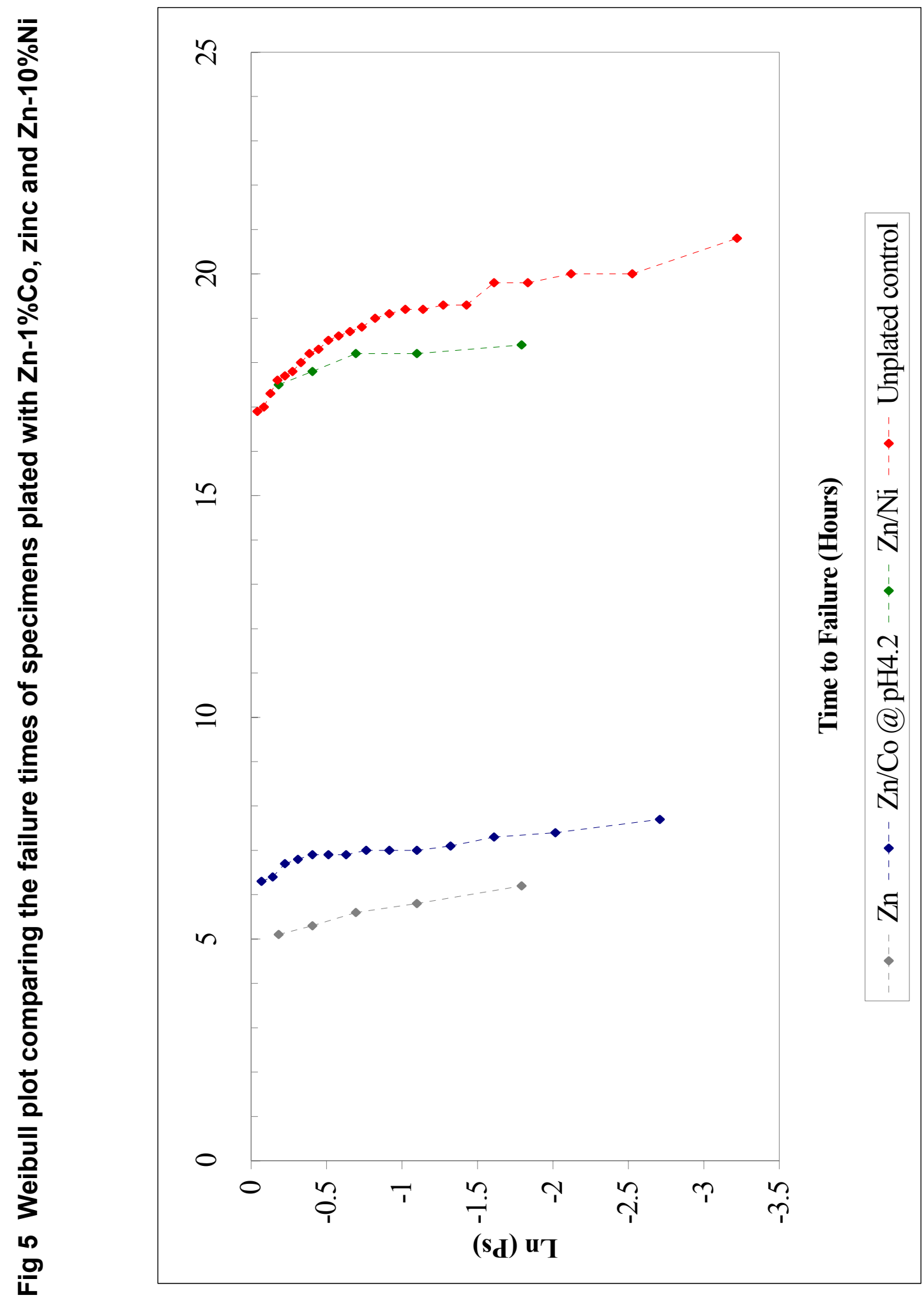




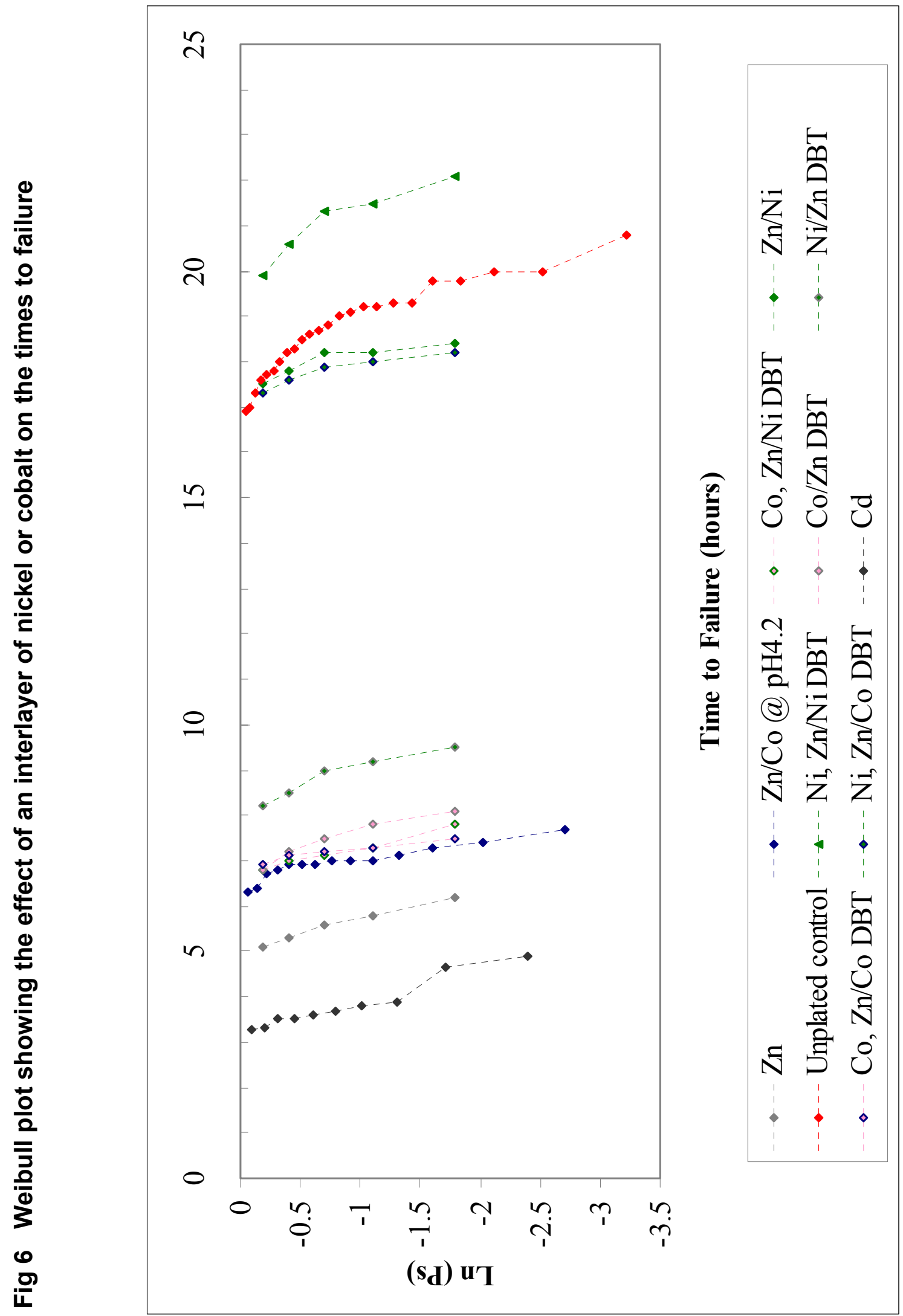




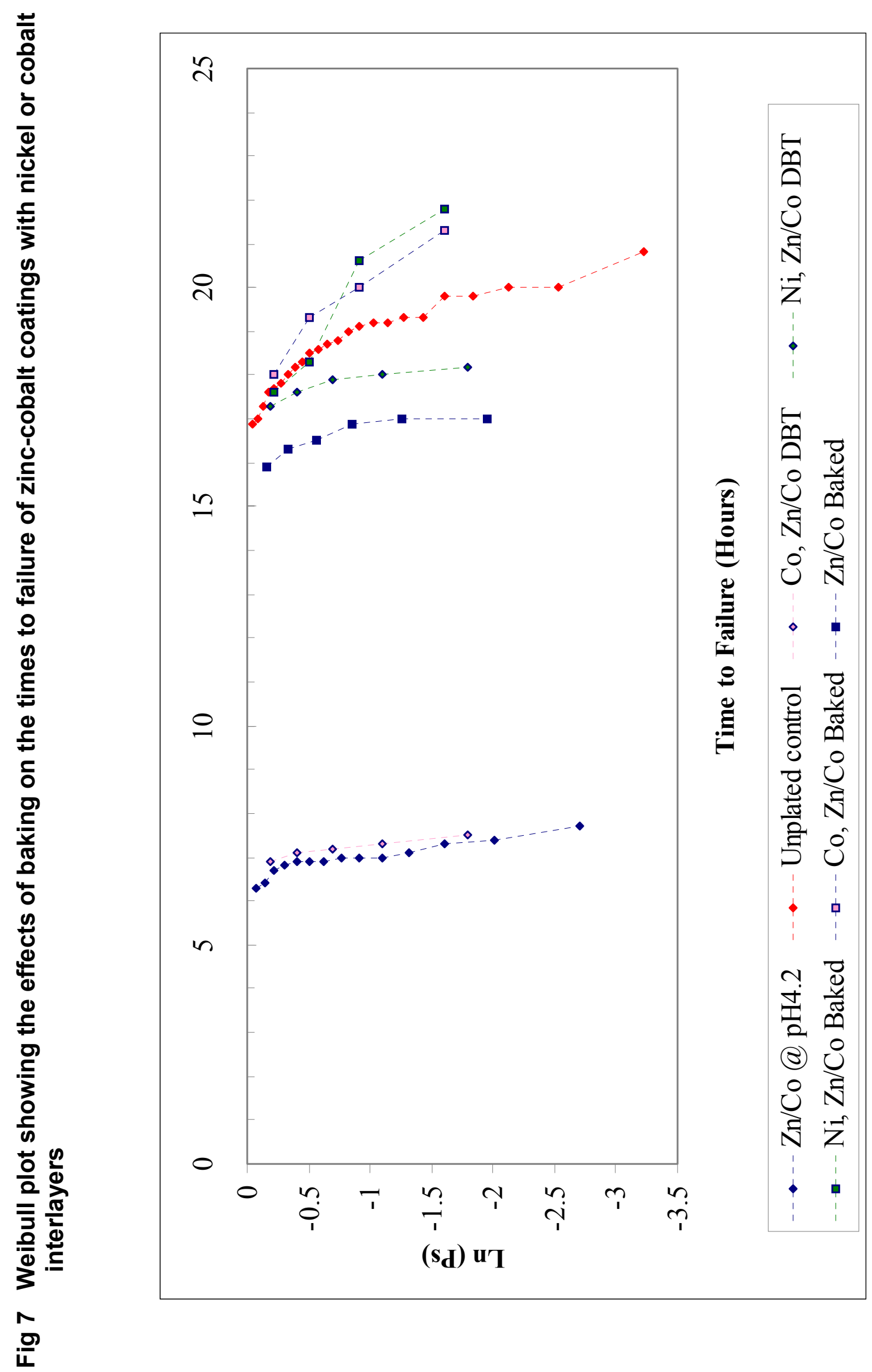




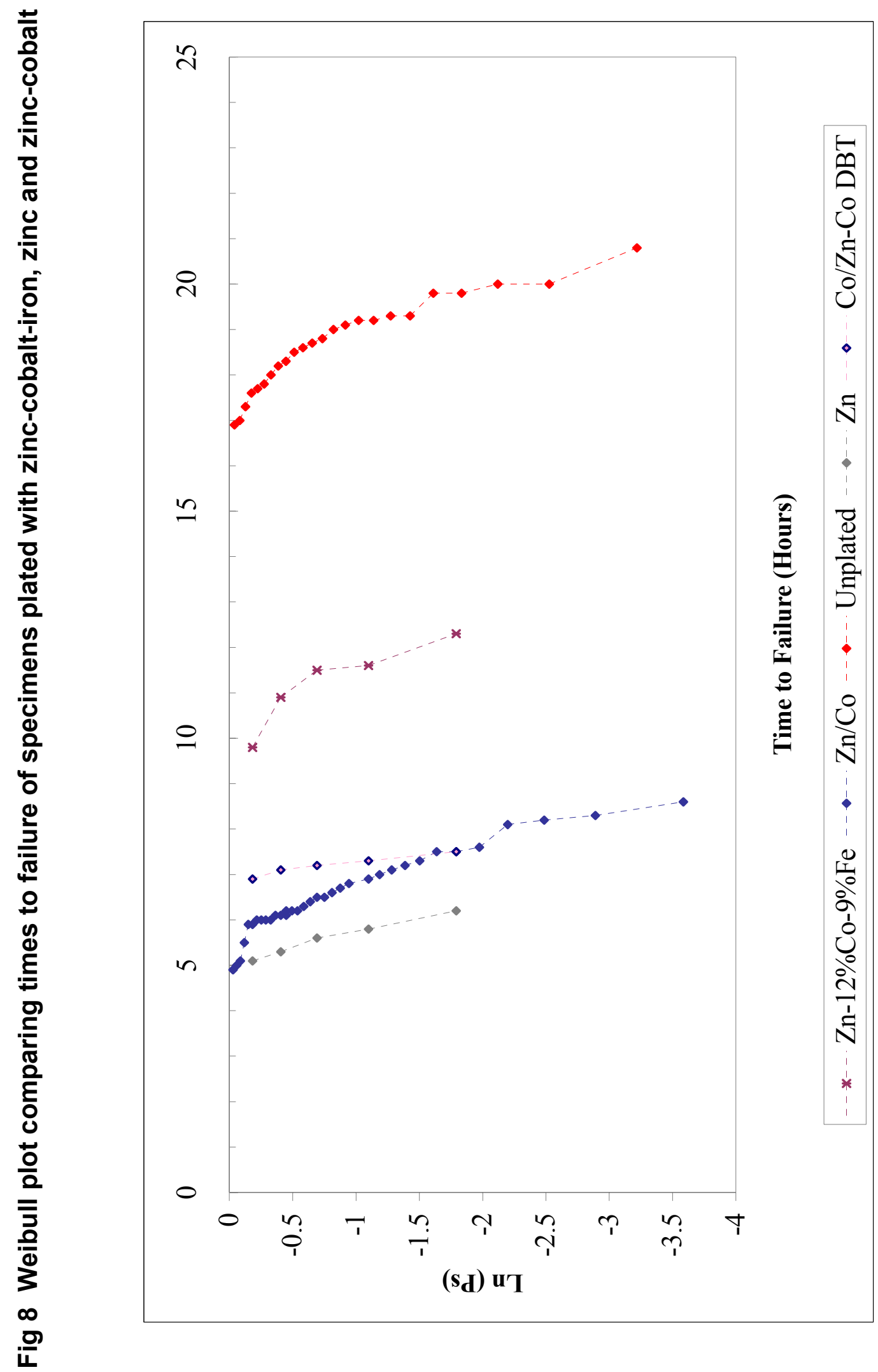


